\title{
DIATHERMY INCISIONS V/S SURGICAL SCALPEL INCISIONS; OUTCOME IN GENERAL SURGERY
}

1. MBBS, MCPS, FCPS Associate Professor of Surgery Civil Hospital Karachi 2. MBBS, FCPS

Assistant Professor of Surgery Civil Hospital Karachi

3. MBBS, FCPS, FRCS

Assistant Professor of Surgery Department of Surgery Unit-II,

Dow University Hospital

OJHA Campus Karachi.

4. MBBS, (MS General Surgery)

Department of Surgery Unit-II, Dow University Hospital

OJHA Campus Karachi.

Correspondence Address: Dr. Khawar Saeed Jamali Associate Professor of Surgery B-302, "Mehran Heights", Block 8 Main Clifton Road, Karachi drkhawarjamali@gmail.com

Article received on:

08/07/2015

Accepted for publication: 30/09/2015

Received after proof reading: 13/11/2015

\section{Dr. Khawar Saeed Jamali', Dr. Naveed Ali Khan², Dr. Muhammad Jawed ${ }^{3}$, Dr. Ubedullah Shaikh ${ }^{4}$}

\begin{abstract}
Objectives: The objective of this study was to compare the outcome of diathermy incisions v/s surgical scalpel incisions in general surgery. Study Design: Cross sectional study. Place and Duration of Study: This study was conducted at surgical unit 7, Sindh Govt. Lyari General Hospital and Dow University of Health Sciences between January to December 2009. Methodology: 100 consecutive patients for elective general surgery were randomly assigned to either group A incision with cutting diathermy $(n=50)$ or group B cold steel scalpel $(n=50)$. Data including demographic details, hospital stay, infection rate and non-infective complications like swelling, bleeding, dehiscence and seroma formation were recorded in both groups to compare the final surgical outcome compared. Results: A total of 80 patients were included in the study, placed alternatively into two groups of 40 patients each with majority being male $(n=$ $61,76.3 \%$ ). The mean age was 22.46 years. The positive predictive value for patients of Group $A$ was $92.5 \%$ while for Group B was $77.5 \%$. When diagnostic accuracy was compared on the basis of Gender for the two groups, the positive predictive value for male patients of Group $A$ and $B$ was $90.09 \%$ and $89.28 \%$ respectively, but for females the positive predictive value of Group $A$ and B was $100 \%$ and $50 \%$ respectively. In Diathermy (Group A) total $20 \%$ patients developed complications and these were seroma formation $(n=4,8 \%)$, wound dehiscence $(n=3,6 \%)$ and wound infection $(n=3,6 \%)$. In Scalpel (Group B) total $26 \%$ patients developed complications $(P$-value $=0.370)$ in which seromas was noted $(n=5,10 \%)$ then wound infection $(n=4,8 \%)$, then wound bleeding $(n=3,6 \%)$ and lastly seroma formation $(n=1,2 \%)$. Hospital stays were also almost similar with mean value 8.24 days in diathermy group and 10.54 days in scalpel group. No remarkable difference in demographics, characteristics and in other variables of patients was noted. Conclusion: We conclude that no significant difference in surgical outcome of both groups (cutting diathermy Vs. steel scalpel). Therefore, use of either technique to create surgical wound merely depends upon preference of surgeon.
\end{abstract}

Key words: Diathermy Incisions, Surgical Scalpel, Incisions in general surgery.

Article Citation: Jamali KS, Khan NA, Jawed M, Shaikh U. Diathermy incisions v/s surgical scalpel incisions; outcome in general surgery. Professional Med $\mathrm{J}$ 2015;22(11):1550-1524. DOI: 10.17957/TPMJ/15.3014

\section{INTRODUCTION}

People have been using cautery for medical treatment from many centuries. In early times cautery appliances and methods were crude when wounds would be sealed with branding iron heated in fire to stop bleeding and as a mean of destroying tumors. ${ }^{1}$ It was first described by Abu Al-Qasim Al-Zahrawi in his work "Kitab Al-Tasrif". ${ }^{2}$ With the passage of time this technique has been modified and now because of advances in technology, fire heated cautery has been replaced by Electrocautery. Despite advancement in technology the safety factor and outcomes of resultant wound by using electrocautery remain under question. ${ }^{3}$ Although there are studies on effects of electrocautery and diathermy in foreign literature, clinical trials at local level are very few. ${ }^{3,4}$

Use of elecrtrocautery or diathermy for skin incision is as old as invention of these devices. Cutting via diathermy is achieved by the use of a very high frequency usually upwards of $100 \mathrm{kHz}$ continuous (unmodulated) current of sufficient voltage (200-500 V). Use of high frequency is to ensure that the patient's nerves and muscles are not stimulated. Lower frequencies could cause twitching and cramps, with consequent intraoperative problems. On the other hand surgical scal- 
pel is very safe; produces a clean incised wound by the physical disruption of tissue, with the minimal tissue destruction. ${ }^{5,6}$

Depending on the voltage used, the electrocautery can have varying effects on the patient's body. ${ }^{2}$ When used for skin or tissue cutting to access surgical site; it causes vaporization of soft tissue by producing temperatures up to $1000^{\circ} \mathrm{C}$ at the tip of electrode, resulting in tissue cleavage. It also causes denaturation of proteins an important factor in coagulation of blood, used to seal off bleeding blood vessels during surgery to keep the site clean and reduce blood loss. Electrocautery is also used in ablation or removal of lesions such as warts, suspected skin cancers. ${ }^{7}$

Diathermy permits the incision to be made quickly, reduces bleeding and causes less postoperative pain; but produces a burn of variable depth in the tissue, which may affect outcome of surgical wound. ${ }^{5,6}$ One additional advantage of cauterization is that it causes cleansing of gets wound sites by killing off many migrating bacteria, causing reduced postoperative wound infection rate..$^{4,8}$

\section{MATERIAL \& METHODS}

100 consecutive patients with proposed elective surgery were enrolled in this study after taking written informed consent. Patients were allocated at random to surgery by either Cutting diathermy (Group A) or by conventional steel scalpel (Group B). Each group comprised of 50 patients. This study was conducted at surgical unit 7 , Sindh Govt. Lyari General Hospital and Dow University of Health Sciences between January to December 2009.

Patients with co-morbidities like diabetes mellitus and hypertension were included in this study to see the impact of these diseases on wound healing. All patients with extreme of ages $(<14 \mathrm{yrs}$ and $>85 y$ rs) were excluded from the study due to the possibility of variability in wound healing; that could affect the study results. Patients with lesions on face were also not included in the study because of possibility of cosmetically bad scar over face due to thermal damage of underlying tissue. Patients having emergency surgeries were also excluded from the study.

All incisions were made after the recommended pre-operative skin preparation and scrubbing. Standardized techniques were used for making skin and deep tissue incisions. A uniform policy of prophylactic antibiotic coverage was used and any established infection was treated as appropriate.

Wounds were classified according to their site and dimension. All incisions requiring closure were closed by layer to layer technique. Wounds were inspected daily in the first 4 post-operative days, then on 7-10th day, 4th week, 8th week and then finally 12 th week to establish final scar appearance and outcome. In case of infection of wounds, signs of sepsis were recorded. Wound infection was defined as the discharge of pus or fluid containing pathogenic organisms. Non-infective complications of wounds such as bleeding, bruising, swelling and post-operative pain were also recorded on follow-up.

The software program SPSS for Windows (version 10) was utilized for all statistical analyses. Frequencies were used to summarize categorical variables like gender distribution, diagnosis, co-morbids and type of procedure. Mean and standard deviation were computed for numerical variables like age distribution, incision length and duration of hospital stay. The Fisher's exact test was used to compare surgical outcome and complications of surgical wound with 0.05 as level of significance..

\section{RESULTS}

The cutting diathermy (Group A) and scalpel cutting (Group B) both were similar in terms of age distribution, sex ratio, diagnosis and co-morbidity. The cutting diathermy (Group A) and scalpel cutting (Group B) both were similar in terms of age distribution, sex ratio, diagnosis and co-morbidity.

The length of incisions in diathermy group (A) were in range between $5-26 \mathrm{~cm}$ with a mean 
length of $9 \mathrm{~cm}$; as compared to scalpel group (B) where the range was between $2-15 \mathrm{~cm}$ with a mean length of $6.6 \mathrm{~cm}$. The technique, used for closure of wounds were similar in both groups. Most commonly adopted was Subcuticular suturing technique, used in 43 patients in group $A$ and in 36 patients in group B. Interrupted suturing technique was used in 6 and 11 patients in Group A \& B respectively. Moreover only 1 patient; wound was treated using mattress suturing technique in Group A, while this technique was used in 2 patients in Group B. As regards use of suture material, Prolene was used in 43 patients in group $A$ and 31 patients in group $B$. Vicryl was less commonly used suture material 12 patients in Group B. Silk was used for a similar numbers of patients $(n=7)$ in each group (Table-III). There was a nominal variation in the surgical outcome of wounds and complications in each group that was not statistically significant; the only exception was post-operative swelling which developed in 5 patients in Scalpel Group(B) while none developed it in the diathermy $\operatorname{Group}(A),(P$ value $=0.036)$. Three patients in Diathermy group (A) developed wound dehiscence while there was none in group B. Seroma developed in both groups: 1 patient in group $A$ and 4 patients in group $B$ this was not statistically significant (P-val$\mathrm{ue}=0.19$ ). Wound haematoma developed only in group $B$, patients $(n=3)$. Wound infection developed in $(n=3,6 \%)$ patients in Diathermy group $(B)$, and $(n=4,8 \%)$ patients in Scalpel group (A). (Table-IV). Mean hospital stay in diathermy group (A) was $8.24+4.96$ and in Scalpel Group (B) $10.54+9.56$ (P-value=0.43), (Table-IV).

\begin{tabular}{|l|c|c|}
\hline & Diathermy (n) & Scalpel (n) \\
\hline Number of patients & 50 & 50 \\
Age (mean \pm S.D. \& & $47 \pm 18(14-85)$ & $37 \pm 17(14-$ \\
range) & yrs & $80)$ yrs \\
Sex ratio ( M:F ) & $44: 6$ & $36: 14$ \\
Diagnosis & & \\
Inguinal hernia & 40 & 26 \\
Umblical/Paraumblical & 1 & 4 \\
Hernia & & 5 \\
Breast fibroadenoma & 0 & 5 \\
Lipoma & 0 & 0 \\
Cholelithiasis & 3 & 2 \\
Goiter & 0 & 5 \\
Hydrocele & 0 & 1 \\
Undescendent Testis & 1 & 0 \\
Pilonidal sinus & 4 & 1 \\
Varicocele & 0 & 1 \\
Breast Carcinoma & 0 & 0 \\
Colonic Carcinoma & 1 & 13 \\
Co-morbidity & & 4 \\
Total & 13 & 9 \\
Diabetes Mellitus & 4 & \\
Hypertension & 9 & \\
& & \\
& & \\
\hline
\end{tabular}

Table-I. Characteristics of Patients

\begin{tabular}{|l|c|c|}
\hline \multicolumn{1}{|c|}{ Procedure } & $\begin{array}{c}\text { Diathermy } \\
\text { Total(n) }\end{array}$ & $\begin{array}{c}\text { Scalpel } \\
\text { Total(n) }\end{array}$ \\
\hline Herniorraphy & 11 & 14 \\
Hernioplasty & 30 & 16 \\
Excision of Benign lesion & 4 & 10 \\
Hydrocelectomy & 0 & 5 \\
Thyroidectomy & 0 & 2 \\
Cholecystectomy & 3 & 0 \\
Orchidopexy & 1 & 1 \\
Colonic resection & 1 & 0 \\
Ligation of Varicocele & 0 & 1 \\
Mastectomy & 0 & 1 \\
\hline \multicolumn{2}{|c|}{ Table-II. Type of Procedures } \\
\hline
\end{tabular}

\begin{tabular}{|c|c|c|c|}
\hline & $\begin{array}{c}\text { Diathermy } \\
\text { (n) }\end{array}$ & $\begin{array}{l}\text { Scalpel } \\
\text { (n) }\end{array}$ & P-Value \\
\hline $\begin{array}{l}\text { Length of Incision (Mean } \pm \text { S.D. \& range) } \\
\text { Closure Technique } \\
\text { Sub-cuticular } \\
\text { Interrupted } \\
\text { Mattres } \\
\text { Suture material } \\
\text { Prolene } \\
\text { Silk } \\
\text { Vicryl }\end{array}$ & $\begin{array}{c}9 \pm 3.3(5-26) \mathrm{cm} \\
43 \\
6 \\
1 \\
43 \\
7 \\
0\end{array}$ & $\begin{array}{c}6.6 \pm 2.3(2-15) \mathrm{cm} \\
37 \\
11 \\
2 \\
31 \\
7 \\
12\end{array}$ & $\begin{array}{l}0.32 \\
0.33 \\
0.19 \\
0.50 \\
\\
0.18 \\
0.22 \\
0.0004\end{array}$ \\
\hline
\end{tabular}




\begin{tabular}{|l|c|c|c|}
\hline & Diathermy (n) & Scalpel $\mathbf{( n )}$ & P-Value \\
\hline Wound healed without complications & 40 & 37 & 0.458 \\
Wound with Complications & & & \\
Seroma formation & 10 & 13 & 0.370 \\
Wound dehiscence & 4 & 1 & 0.199 \\
Wound swelling & 3 & 0 & 0.132 \\
Bleeding/haematoma & 0 & 5 & 0.036 \\
Wound infection & 0 & 3 & 0.132 \\
Hospital stay/Duration (Mean \pm S.D.) & $8.24 \pm 4.96$ days & $40.54 \pm 9.56$ days & 0.510 \\
\hline
\end{tabular}

Table-IV. Surgical outcome, Complications \& Duration of Hospital stay

\section{DISCUSSION}

With time, many techniques have been developed to incise skin, to excise lesions or to approach deeper tissues or organs; but the surgical scalpel and diathermy are the two most popular methods among surgeons to create surgical incisions.

This study compared the above two methods for creating surgical incision in terms of wound complications and effect on hospital stay. To exclude confounding variables there were similar type of patients in both groups in terms of distribution of age, sex ratio, diagnosis, co-morbids, type of procedure performed; even skin closure technique and type of suture material used were also same in each group. In this study, the patients were from the specialty of general surgery, while most previous studies were based on specific cases..$^{9,14}$ Patients with co-morbids conditions like diabetes mellitus and hypertension were the included in this study to observe it these diseases have an effect on wound healing, but no significant difference was found; complication rates were similar as in other studies that had patients without co-morbids. ${ }^{11,15,16}$

In this study there was a large number of cases with seroma formation $(n=4,8 \%)$ in the diathermy group but less bleeding ( $n=0,0 \%)$ post operatively was compared to the scalpel group that had seroma formation is $(n=1,2 \%)$ and bleeding is $(n=3,6 \%)$, as in Kathaleen et $\mathrm{al}^{17}$ Dixon et $\mathrm{al}^{18}$ and Miller et $\mathrm{al}^{16}$ studies. Patients with seroma development were treated with alternate stitch removal to drain out serous and fluid, later on resurfaced if needed. Wound dehiscence which is also a significant complication of diathermy usage, es- pecially in abdominal midline incision; ${ }^{15,19,20}$ was noted in this study $(n=3,6 \%)$.Cases with wound dehiscence were managed by tension suturing and nutritional supplements. Wound infection rate was almost equal in both groups; $(n=3,6 \%)$ in Diathermy group $(A)$, while $(n=4,8 \%)$ in Scalpel group (B) which is similar to what has been reported in international literature. ${ }^{11,21}$ Swabs were taken from infected wounds to identify pathogenic organisms, and patients treated according to culture reported received.

Neither of above mentioned complications significantly affect the surgical outcome and hospital stay of patients, with mean value of hospital stay in diathermy group (A) was $8.24 \pm 4.96$ and in Scalpel Group (B) $10.54 \pm 9.56(P$-value $=0.43)$.

\section{CONCLUSION}

In Conclusion it would appear there is no statically significant difference when diathermy or scalpels are used to incise skin by an experienced surgeon.

Copyright $\odot 30$ Sep, 2015.

\section{REFERENCES}

1. Longaker, M T. Gurtner, Geoffrey C. Diathermy or Surgical Scalpel for Abdominal Skin Incisions: What Is the Impact On Clinical Practice? Ann of Surgery 2011. Jan;253( 1);14-5.

2. Ahmad N Z, Ahmed A, Meta-analysis of the effectiveness of surgical scalpel or diathermy in making abdominal skin incisions. Ann Surg 2011.Jan;253(1);813.

3. Shamim M. Diathermy vs. Scalpel Skin Incisions in General Surgery: Double-Blind, Randomized, Clinical Trial. World J Surg 2009; 33:1594-99. 
4. Brent M, Luba N, Rhonda E, Kyle F, et al. Ultrasonic and Nonultrasonic Instrumentation: A Systematic Review and Meta-analysis. Arch Surg 2008; 143(6):592-600.

5. Silverman, E. B., R. W. Read, C. R. Boyle, R. Cooper, W Miller. W and McLaughlin R. M.. "Histologic Comparison of Canine Skin Biopsies Collected Using Monopolar Electrosurgery, Co2 Laser, Radiowave Radiosurgery, Skin Biopsy Punch, and Scalpel." Vet Surg 2007; 1: 50-56.

6. Stavroulaki, P., C. Skoulakis, E. Theos, N. Kokalis, and D. Valagianis. "Thermal Welding Versus Cold Dissection Tonsillectomy: A Prospective, Randomized, Single-Blind Study in Adult Patients." Ann Otol Rhinol Laryngol 116, no. 8 (2007): 565-70.

7. Cook, L. A., A. Pun, H. van Vliet, Gallo M. F., and Lopez L. M.. "Scalpel versus No-Scalpel Incision for Vasectomy." Cochrane Database Syst Rev, no. 2 (2007).

8. Chrysos, E., E. Athanasakis, S. Antonakakis, E. Xynos, and O. Zoras. "A Prospective Study Comparing Diathermy and Scalpel Incisions in Tension-Free Inguinal Hernioplasty." Am Surg 71, no. 4 (2005): 326-29.

9. Sheikh, B. "Safety and Efficacy of Electrocautery Scalpel Utilization for Skin Opening in Neurosurgery." Br J Neurosurg 18, no. 3 (2004): 268-72.

10. Stolz, A. J., J. Schutzner, R. Lischke, J. Simonek, and P. Pafko. "Is a Scalpel Required to Perform a Thoracotomy?” Rozhl Chir 83, no. 4 (2004): 185-88.

11. Kearns, S. R., E. M. Connolly, S. McNally, D. A. McNamara, and J. Deasy. "Randomized Clinical Trial of Diathermy Versus Scalpel Incision in Elective Midline Laparotomy." Br J Surg 88, no. 1 (2001): 41-44.

12. Duxbury, M. S., Blake S. M., A. Dashfield, and Lambert A. W.. "A Randomized Trial of Knife Versus Diathermy in Pilonidal Disease.” Ann R Coll Surg Engl 85, no. 6 (2003): 405-07. 16.

13. Mostafa Shehata. "The Father Of Islamic Medicine: An International Questionnaire”. Journal of the International Society for the History of Islamic Medicine 2002 ; 58-59:58.

14. Franchi, M., F. Ghezzi, P. L. Benedetti-Panici, M. Melpignano, L. Fallo, S. et al. "A Multicentre Collaborative Study on the Use of Cold Scalpel and Electrocautery for Midline Abdominal Incision.” Am J Surg 181, no. 2 (2001): 128-32.

15. Ziv, Y., Brosh T., Lushkov G., and Halevy A.. "Effect of Electrocautery Vs. Scalpel on Fascial Mechanical Properties After Midline Laparotomy Incision in Rats." Isr Med Assoc J 3, no. 8 (2001): 566-68.

16. Porter KA, 'Connor.O Rimm S.E, Lopez M. Electrocautery as a factor in seroma formation following mastectomy. Am J Surg. 1998 Jul; 176(1):8-11.

17. Liboon, J., Funkhouse $\mathrm{W}$ and D. J. Terris. A Comparison of Mucosal Incisions Made By Scalpel, Co2 Laser, Electrocautery, and Constant-Voltage Electrocautery. Otolaryngol Head Neck Surg 1997; 116: 37985.

18. C. D. Johnson, Serpell J. W. Wound infection after abdominal incision with scalpel or diathermy. Br. J. Surg. 1990; 77: 626-627.

19. Dixon, A. R., and Watkin D. F. "Electrosurgical Skin Incision versus Conventional Scalpel: A Prospective Trial.” J R Coll Surg Edinb 35, no. 5 (1990): 299-301.

20. Groot, G., and Chappell. E. W. "Electrocautery Used to Create Incisions Does Not Increase Wound Infection Rates." Am J Surg 167, no. 6 (1994): 601-03.

\begin{tabular}{|c|l|l|}
\hline \multicolumn{3}{|c}{ AUTHORSHIP AND CONTRIBUTION DECLARATION } \\
\hline Sr. \# & \multicolumn{1}{|c|}{ Author-s Full Name } & \multicolumn{1}{c|}{ Contribution to the paper } \\
\hline 1 & Dr. Khawar Saeed Jamali & Conception and design \\
2 & Dr. Naveed Ali Khan & $\begin{array}{l}\text { Statistical expertise, Critical } \\
\text { revision of the article for } \\
\text { important intellectual } \\
\text { content } \\
\text { Drafting of the article }\end{array}$ \\
\hline 3 & Dr. Muhammad Jawed & $\begin{array}{l}\text { Critical revision of the article } \\
\text { for important intellectual } \\
\text { content }\end{array}$ \\
\hline 4 & Dr. Ubedullah Shaikh & \\
\hline
\end{tabular}

